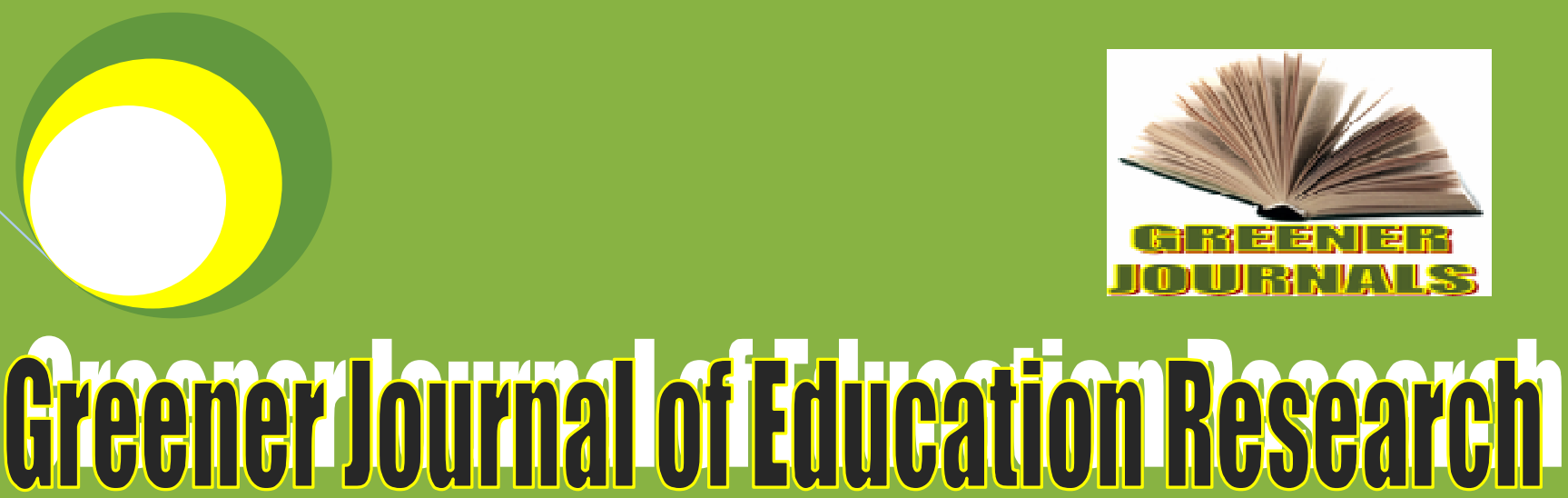

ISSN: 2276-7789 ICV: 6.05

Subject Area of Article: Distance Education

Making it happen with distance education: Critical concerns for student support services in Open and Distance Learning

By

Miriam Chitura

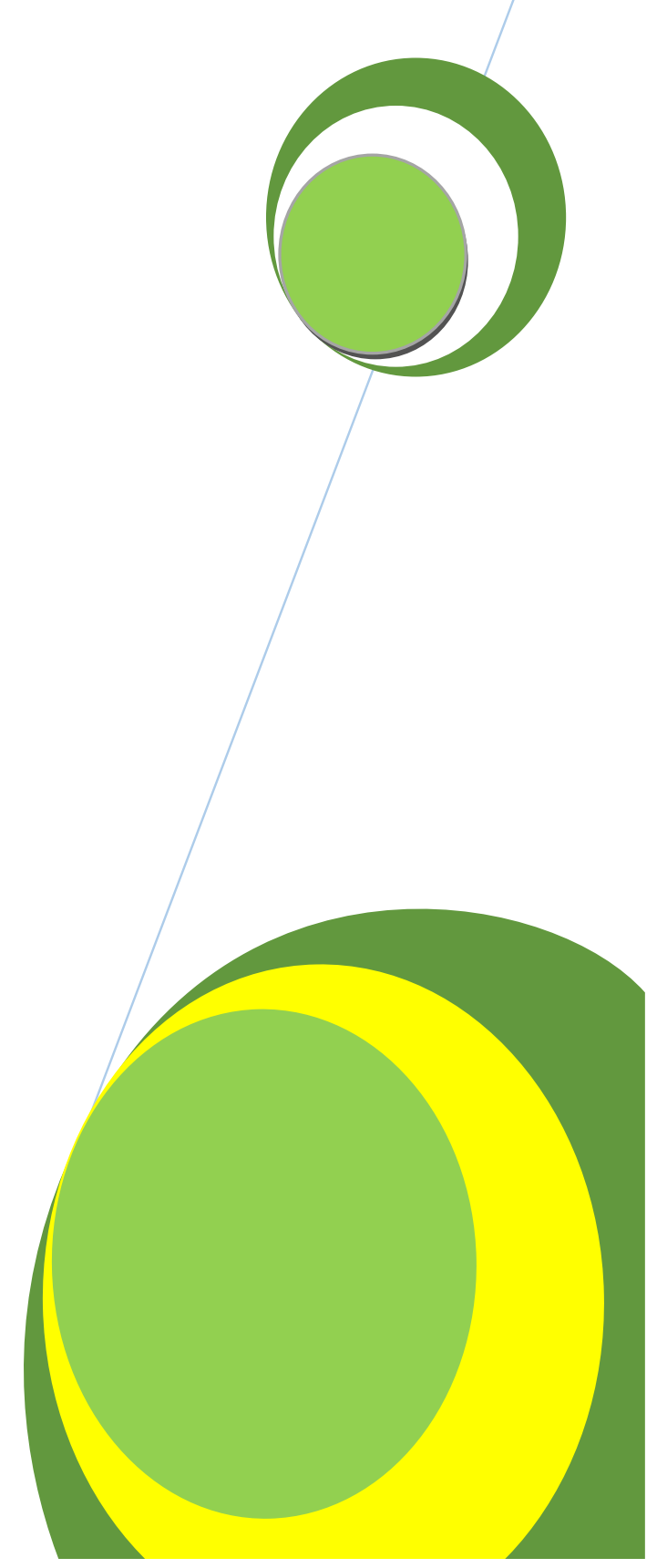




\title{
Making it happen with distance education: Critical concerns for student support services in Open and Distance Learning
}

\author{
Miriam Chitura
}

\author{
Department of Health Sciences, Faculty of Science and Technology, The Zimbabwe Open University, (ZOU), Box \\ MP 1119 Mount Pleasant, Harare. \\ E-mail: miriamchitura@yahoo.com \\ All correspondence to: Miriam Chitura \\ 22 Houghton Park Road, Waterfalls Harare. Cell: 0772383402
}

\begin{abstract}
The journey through ODL is not an easy task. Dropout rate continues to escalate in most ODL programmes, with only the determined students making it to the end. It is imperative that ODL institutions put in place effective support systems for students to fall back on. ODL students are faced with a lot of emotional and psychological obstacles as they navigate through their educational journey.

For e-learning, transactional distance is 'the distance between teachers and learners'. Both tutors and students experience a sense of separation that is caused by more than simple physical distance. This distance is psychological. There is also a communication gap, a space of potential misunderstanding between the inputs of instructor and those of the learner. This is created, in part, by the physical distance. Students may feel isolated or disconnected. This results in reduced motivation, reduced engagement that may result in high attrition. When offering Mathematics and Statistics programme by distance, one needs to consider factors that affect the transactional distance. i.e. structure and dialogue.

In this regard, students need the right tools, guidance and support. The authors here make an analysis of the registration process onto the Mathematics and Statistics program by DE, look at the professional and technical support the students receive as they navigate through their journey. Other variables such as the factors contributing to high dropout rates, various delivery modes and impact on the pass rates are also presented. The paper aims to develop a student support package for those undertaking BSc Mathematics and Statistics programs.

It is hoped that the study will be extended to other programmes in the faculty and maybe to all universities that conduct Mathematics and Statistics programmes by ODL.
\end{abstract}

Keywords: dropout rate, support systems for students, psychological obstacles, reduced motivation.

\section{INTRODUCTION}

Student support and quality assurance are critical if the ODL is to realise its goals the quality of programmes enhances graduate recognition and employability. Attaining quality involves a lot of activities. These include setting up institutional quality assurance blue-print, which stream-lines all the procedures and processes. Stakeholder involvement is also important as critiques and new ideas can be given to distance education institutions. Setting up of Student bodies will ensure that student interests are addressed.

It is commonly accepted that Distance Education (DE) institutions should have in place, a sound learner support system. This paper examines learner support services available for BSc Mathematics and Statistics students, looks at the significance of learner support to the learner. The use of ICT in the delivery of Mathematics and Statistics programmes is also discussed. As the field of DE is fairly new especially in developing countries, DE credibility is on the spotlight and care should be taken when delivering programmes. Issues related to graduates recognition and employability need to be taken into consideration.

Learner support is an integral component of the distance education system. The success of distance education is highly dependent on the learner support system in place. By definition, Learner Support Services are those services rendered to the learner in order that they realise their goals. The services could be in the form of Administrative support, where the student gets support during enrolment and during tutorials.

From a central point, the coordinator is expected to give information to students, about fees, available resources, policies, learning materials and other relevant activities. The Coordinator facilitates with the coordination of learning processes including organising tutorials and keeping students' records. 
Besides administrative support, the student also receives tutorial support whereby formal meetings or face to face tutorials are arranged between the tutor and a group of students or the tutor and individual students. The group could also arrange to meet on their own to discuss issues that affect them.

Other forms of tutorial support are tele-conferencing or tele-tuition. Tutorials could also be arranged using the radio, electronic mail or use of compact discs. Feedback through tutor marked assignments is another form of tutorial support distance education students can receive. Comments to the student by the tutor should always be of benefit, as these comments enhance tutorials.

Students receive Guidance and Counselling support services where students are assisted to get into terms with their new roles as students. The counsellor or supporter facilitates on the student's choice of courses. Information related to course prospects in a given programme is also given to students. Students are counselled on study skills, time management including self discipline.

Because students are bio-psychosocial beings who are in continuous interaction with both the external and internal environment, the Counsellor needs to be holistic in his approach. The Counsellor gives support to students in order that they are able to cope with personal problems and social pressures that may impact on their studies. The support services should ensure that the students are kept motivated and they are able to cope with some of the stressors in life.

'Distance Education learners need support because they have uncertainties about getting to their destination, and this support is rendered through dialogue with others', (Modesto and Tau2009).

Supporters of distance education learners need to have a solid understanding of the characteristics of the learner if the services are to be beneficial.

The issues discussed below will assist to highlight on some of the significance of support services to the DE learner.

Learner support plays a significant role in the orientation process of students into their new role as distance education learners. Learner support introduces learners to distance education, gives information on student's expectations. Learner support also outlines the processes and procedures students will go through during the course of their training.

Learner Support ensures that students get information from such team players as managers, course coordinators, material producers, regional coordinators as well as non-subject specialists, on registration, fees, tutorial services, course structure, assignments, examinations as well as other resources available. Students are issued with relevant course materials.

The distance education learner is supported to 'learn how to learn' and to dialogue with others. The learner support assists course developers to design materials that communicate to the student. Activities that are in-cooperated in the modules enhance understanding of concepts as well as encourage students to carry out further research on a given assignment.

Whilst good modules could reduce distance between the tutor and the learner, this could further be achieved through organised tutorials. The learner support plans and arranges for face to face tutorials for the tutor and the group. A one on one meeting could be arranged if there is need. Student could also meet as a group and discuss issues that affect them. Thus tutorials provide an opportunity for tutors and learners to meet and clarify concepts. Socialisation process also takes place as students meet as a group.

The distance learner has several challenges that impact on her or his learning. These include work obligations, psycho-social and language problems. As such, a sound learner support system is imperative in order that students receive guidance and counselling as required. Some students might be experiencing distance education for the first time. They would therefore need counselling on time management and self-discipline.

In distance education, the learner supporter needs to have a clear understanding of distance education and the processes involved. An insight into the type of environment of distance education, the characteristics of the learner as well as knowledge of stages involved in materials production is critical. An effective learner support system in a distance education institution is of great significance as it assists distance education learners to realise their goals - of completing their studies.

Library services, use of ICT, that is the internet, e-mail, tele-conferencing or tele-tutoring are all services that complement learner support. The learner supporter and the support services he provides to the learner play a significant role to the success of any distance education institution.

Learner support services of an institution in one of the SADC countries were evaluated. By definition, 'Evaluation is the collection, analysis and interpretation of information about any aspect of a programme of education and training, as part of a recognised process or judging its effectiveness, its efficiency and any other outcomes it may have (Thorpe 1988). The institution evaluated is an Open and Distance Learning University with a vibrant learner support system in place. The support services to the students include:

\footnotetext{
1. Administrative Support Services

2. Tutorial Support

3. Guidance and Counselling
} 
The University operates on the basis of administrative regions. At each regional centre, is a coordinator, who is employed full-time. He/she reports to the National centre. All the different programmes have such similar structures in place. The role of the coordinator is that of student support through coordination of all learning activities in the region. He/she is involved with timeous student enrolment. Information from the national centre is distributed to the Regions. The coordinator distributes the information to the students. He/she organises tutorials, distributes assignments and administers examinations through the leadership of a director.

The system was found to be working very well and students received effective support services. However, the system has some disadvantages especially to students who come from long distances. Learners may not have enough money to travel to the Regional Centre regularly. As such, information may not get to them on time.

To counter the problem of distance, the institution is on a drive to establish district centres in every region. The major aim is to take the learner support services closer to the learners. To date, three district centres have already been identified and are functional. These centres are manned by part-time staff who, in most cases are also part-time lecturers on some of the programmes. With time, it is hoped that learner support services will be decentralised to most of the districts.

Currently, all tutorials and student guiding and counselling activities take place in the regions. It is only decentralised to the three afore mentioned districts and it is hoped that there will be more decentralisation to other districts. The current support system needs to be complemented with new technology such as the use of computers. Computers can play a significant role in student support in DE.

In Distance Education, the issue of communication is critical. Language is the basis for communication. However, computers could be utilized to enhance the communication process in support of student learning. Computer assisted learning has great potential in transforming the distance education scenario. The success of computer assisted learning lies in the ability of both the tutor and the learner to use the computer. Computers can basically assist to connect learner to their tutors or learners to other learners, to share ideas, experiences and solve academic problems. The discussion below will highlight on the potential computer assisted learning has in supporting DE learners.

Several issues have to be considered before a distance education institution decides to embark on computer assisted learning programmes in an endeavour to support students. The institution has to be clear on its objectives before embarking on to computer assisted learning. The distance education institution needs to introspect and be clear on the issues of viability, availability of computers, the infrastructure, support services and sustainability of the program.

Learner support services benefit a lot from the use of technology. Computer assisted learning is vital to distance education. Computers are used for information communication and storage, student teacher interaction, as well as learner to learner interaction. There is a positive enhancement in the administrative systems. Staff and students can access information for research on computers. Use of computers enhances interpersonal communication amongst staff, intra-faculty and inter-faculty, as well as communication with students and other stakeholders. It also supports students in that those who have computer access can embark on e-learning.

Computers have a great potential in transforming distance education in that, where there is a sound infrastructure, a large number of students can be accessed within a short period of time and at very little cost, through the internet using e-mail or e-tutoring. Currently, a number of learners on the DE program are assisted by internet to do their assignments. Learning is facilitated by internet through the use of computers. Computers can transform distance learning if students use compact discs instead of modules. The use of CD's would greatly reduce expenses related to module production especially in developing countries where resources are scarce. Through computers, tutorials could be conducted through video conferencing.

Computer assisted learning could be used to support and assist the students and faculty members to access information about other distance education institutions. Students can continue to study with institutions of their choice even if they moved to other countries. Use of computers in distance education enhances research potentials of institutions. A wider variety of information could be accessed through the computer on the internet, through a variety of internet search programmes. Institutional repositories could be put on computers and these could be accessed through institutional websites. This kind of support, if availed to students, would assist to reduce student frustrations

Computers could make the lives of distance education students as well as management, a lot better, if the facility is used for results publication. Students would not need to travel for long distances to get their results at centres of learning. Communication with coordinators would be done at a distance to avoid transport cost. However, at times even though problems are solved over the internet or the phone, the student would also want to be filled in by the 'tutor's voice'.

Through the use of computers, researches and tutorials could be presented on Power Point to a large audience. Summaries of guidelines, policies and processes could be presented on power point as well.

It appears computer assisted learning is slowly gaining momentum in distance education especially in developing countries. The use of computer assisted learning has the advantage that, one can access local and international students. Computers assist the learner to hear and see the lecturer in a manner they would experience in face-to-face tutorials. 
Tutor-learner interaction is enhanced and distance between the learner and the tutor is reduced. Use of CD ROM is an addition to the learner library. As mentioned before, learners can access institutional repositories on their websites as well as access information from other institutions. Use of computers, besides reducing the distance between the tutor and the learners, facilitates for immediate feedback when tutor interacts with the learner. The learners can enjoy all the services in the comfort of their own homes.

Most distance education learners and tutors have to learn how to use computers, if computer assisted learning is to be successful. Use of computers reinforces student acquisition of knowledge on computer use, and they develop communication skills. This encourages students to become more active in the learning process. Students participate in the guided construction of knowledge. Information handling skills are also enhanced through the use of computers.

Whilst tutor-student interaction is enhanced through use of computer assisted learning, students are also linked to other students and the international world. This enhances the socialization process, as the students share their experiences as well as academic challenges.

Computer assisted learning can greatly transform distance education systems. Access to students who are dispersed in many parts of the world is made possible. Through the use of computers, universities have managed to continue servicing students including those who have migrated to over-seas countries, in search for 'greener pastures'. In many institutions, computers are used to generate Personal Identification Numbers (PINs) during student registration. Computers have been used to consolidate student data base. The institutional website has been used to publish examination results and display information about the institution. The local and international communities can access this information, that includes the available programs and faculties, link persons as well as other relevant services. The publication of results on the website has a positive impact to both the student and the tutor, in that, the method is less costly. From experience in the SADC region, the use of computer assisted learning is confined to cities and towns where electricity and infrastructure are available. The route of the production of CD's is opted for because of its efficiency and the perceived economic advantages. In most cases, this has proved to be cheaper for the institution as the cost of module production is extremely limiting. However, students coming from the remote areas, still have to rely on print modules, as they do not have computer facilities. Some donor funded programs such as the World Links, assisted to increase computer accessibility to students in Zimbabwe, even those from remote areas, where some infrastructure was developed.

Whilst the general perception is that, computer assisted learning could have great potential in transforming distance education, the need to have a well development infrastructure before embarking fully on the programme is critical. The relevant ministries, such as, the Ministry of Higher and Tertiary Education, in Zimbabwe, for example, needs to develop policies on computer assisted learning. There is need to allocate resources to develop and strengthen ICT. Support, in terms of training personnel in the use and maintenance of the equipment, is pivotal to the success of the programme.

Once a robust computer infrastructure is put in place, there is need for programme sustainability. Continuous evaluation on the performance of computer assisted learning should be carried out through research, in order to identify gaps and improve on the delivery system. Participation by students and other stakeholders on the evaluation of the computer assisted learning program is necessary in order to identify gaps and improve on the system.

Computer assisted learning, if adequately supported, has great potential in the enhancement of quality delivery of distance learning. The use of electronic mail enables local and world -wide linkages between faculties and learners, learners and other learners as well as inter-faculty communication. Members exchange and share ideas. The system is quick and efficient. Modules are attached as files and delivered by e-mail to students. However, the inclusion of the 'tutor's voice is important in computer assisted learning as technology is only a signal or message carrier and appropriate language is chosen to communicate content' (Modesto and Tau 2009).

Computer assisted learning has its own limitations. Students who do not have access to computers are left out. The system requires rural electrification that may demand a lot of resources as is the case for most developing countries. Data may get lost in the computer and as such, there is always need for back-up with hard copies. Institutions need to be tight on security items to avoid tempering with information by some unscrupulous elements. Receipt of documents send by e-mail should always be acknowledged as students may fail to respond to instructions due to technology failure.

Whilst DE practitioners may endeavour to push for learner support, several factors influence the growth of Distance Education in terms of communication technology in a country. Some such factors include the Government philosophy, human resource expertise as well as availability of financial resources.

The government is a major player in influencing the growth of distance education compliant communication technology. What the government believes in with regards to the technology will result in its support for the project. In an effort to establish best modes of delivery in distance education, institutions and the government identify leaders in distance education and draw lessons from them. The need for technology in distance education is established. The government assigns personnel who work on a feasibility study for the programme. Questions related to how best other institutions in developing countries manage technologies in distance education programmes are often asked. 
Institutions and the government may decide to send personnel who would under-study sister institutions in the region or other countries abroad. Seconded personnel would then come back home and implement programmes on distance education compliant communication technology. The success of the program is dependent on government initiatives and support.

For the government to appreciate and support the growth of the communication technology there has to be clearly identified advantage to the use of the technology. It is through the identified advantages that there is appreciation and support to the technology which will result in its growth. The government passes legislation in the initial stages and in some instances, it can approach or it identifies non-governmental organisations it can enter into partnership with, in order to establish and strengthen ICT programs for the country. Some governments in the region of Zimbabwe received a lot of support from World Links, a non-governmental organization that enhanced ICT accessibility to even the most remote corners of the country. In virtual tutoring, the intended parties engage in tele-learning. Several forms of ICT support are used depending on the objectives of the institution. Ndereya et al (2003) . The current knowledge has revealed that a lot, in terms of student support, could be achieved through the use of distance education compliant communication technology.

This includes the ability to store huge volumes of information. Some of the administrative work could be easily accomplished through the use of technology. A good example is the use of on-line services. Students can enjoy vital services at the click of a button and without necessarily having to travel long distances to access information. Student access reading materials, assignment questions and examination results. As more students continue to enjoy the services, there is always growth in the technology in that there is sustainability of the program as students will pay for the services.

With the technology, students can engage in group interactions. Tutors deliver tutorials through the technology, thus enhancing geographical reach through the e-tutor. Enrolment, registration and information about fees, is given on-line. Distance education compliant communication technology is also used for student support, and this include web based e-learning, video conferencing and many others as mentioned before. These are all modes used in distance education to reduce the distance between the learner and the tutor. The government philosophy on distance education compliant communication technology is influenced by the ability of the technology to enhance the effectiveness of distance education. Technology is becoming more popular and with technology, there is no fast or slow learner. However, the technology can have its own disadvantages in that, the computer can express the sentiments of the teacher. If it is not video conferencing, students cannot ask questions as they can only follow what is given. However, it should always be understood that government philosophy plays a major role in influencing the growth of distance education communication technology.

Other factors to be considered are, the availability of trained personnel in distance education compliant communication technology. The use of technology requires that the tutor and the learner be trained. Knowledge of what technology can do to influence distance education is vital. Take an example of computer conferencing, the student and tutor are networked. The learner can hear as well as see and talk to the tutor. Learners develop communication skills and, play a more active role in guided construction of knowledge. Modesto and Tau (2009). Training of both the tutor and the learner in the use of technology is inevitable if the system is to succeed. The issue of expertise in the use and maintenance of technology cannot be over-emphasized. Even though the country may have good computers in place, training in the use of the available technology is vital. Institutions need to deliberately move into training of their personnel through staff development programs.

It is only through training that tutors can appreciate what technology can do to alter the scenario in distance education. Computer skills also permit the development of effective accounting procedures, Thorpe (1993). However, when introducing the technology, it is always best to get the support of stakeholders. Members need to be involved at all levels of the development of the programme to ensure ownership. This also impacts on the growth of technology.

The final and most vital aspect that influences growth is availability of funds. Whilst the government may have positive beliefs about the use of technology and its advantages in the field of $D E$, the availability of financial support is vital. Funds will enable institutions to train personnel and to put the necessary accessories.

Technological support to the learners needs to be viewed as of great importance as it contributes greatly to the success of DE programs. The factors discussed above that influence the growth of distance education compliant communication technology in a country are government philosophy, availability of experts in the country as well as financial strength of a country. The knowledge and appreciation of what the technology can do to enhance distance education processes is an important factor in the development of technology.

Student support services assists to reduce challenges faced by DE learners in developing countries. Before becoming a success story, distance education institutions face an uphill struggle, in terms of fighting stigma and discrimination. The transition from known to unknown is not easy for many. Members of communities who trained and are used to the conventional type of education, fail to appreciate distance education, and are likely to ask questions with regards credibility of distance education. A lot of questions are commonly raised. An attempt will be made to discuss issues pertaining to distance education credibility. 
For many countries in the developing world, the concept of distance education is a growing phenomenon. It appears distance education is not readily appreciated by many including those who teach on distance education programs. Staff development has been instrumental in bringing about change of view. The questions commonly raised about the credibility of distance education are variable.

Questions raised could be categorized into those questions pertaining to administrative issues including student support, questions related to the processes or ways the distance education programs are delivered and then, questions related to the credibility of the product, that is the graduates. From the administrative aspect, people would want to know why they embark on distance education as opposed to conventional type of education.

People also want to know who is delivering the distance education programs and the qualifications they hold. A lot of criticisms can be raised when the institution deployed personnel who are under-qualified, to tutor. Questions related to the acceptability of the programs are raised.

Who enrols for distance education? Are they the poor performers who fail to qualify at conventional institutions? Who are the faculty members, what training did they receive and where? All these questions are asked in order to assess credibility of the administrative aspect of the distance education. At times, people may want to know the bodies funding the distance education program, as well as sustainability of the program. In terms of program delivered, questions asked relate to acceptability of qualifications nationally and internationally. No one would want to train and become redundant. Program evaluation becomes key at all stages. Evaluation can contribute to the effectiveness with which a program is implemented, and it is also central to good project management, Thorpe (1993).

Questions related to the delivery process revolve around duration of the programs. Perceptions might be that students on a distance education program should take longer to train than those in conventional institutions because of the limited contact time they have with the tutor. What quality product do modules and face to face tutorials bring? The issue of whether there is adequate interactivity between the learner and the tutor in distance education is also raised. It has however emerged that most of these fears are a result of lack of information about distance education. Questions are also asked on whether 'schools without walls' can really produce quality products. Again on the delivery processes, questions may be asked on whether there has been any success stories on distance education. Questions related to the ability of distance education institutions to address challenges, are also raised. Student support services issues are also topical when one is considering credibility of an institution.

Doubts in the ability of DE management to plan for successful future for the institutions and programmes may also be raised. Whether the institutions have the capacity to address their challenges is a critical question that may also be asked. To develop a DE system is to start or cause it to exist and make it grow. Developing something involves planning for it, Modesto and Tau (2009) Again questions are asked on the capacity of implementers to effect institutional growth and development. Project evaluation, is important at all stages. Questions related to whether product offered is of quality can best be addressed through evaluation, as it will reveal the effects of our own actions, so as to judge their value, Thorpe (1993).

In terms of the products, questions are asked on comparability of graduates from distance education to those from the conventional institutions. Questions raised seek to know whether distance education graduates can perform to the same level or better. There are programs that train on practical skills competencies. Questions raised for such programs relate to whether graduates receive adequate exposure, mentoring and hands on experiences in their subject areas. There has always been a challenge in trying to satisfy the requirements for practicals in distance education. Questions on whether the graduates are equally comparable on the job market, with those who trained at conventional institutions, are also raised. In order to support graduates in terms of employability, DE institutions need to improve on their image.

Whilst distance education has achieved to reach out to many people who might have missed the opportunity of going through tertiary education, a lot more needs to be done to educate populations. An awareness campaign would assist to reduce or remove stigma and discrimination against distance education graduates.

The quality of distance education product is questioned by those who are not quite familiar with distance education. Questions may also be asked on the potential of research in distance education, and whether the findings can reliably be utilized for future planning purposes. However, no mater the number of questions people may ask about the credibility of DE, the onus is upon DE practitioners to prove their worth. There is need to remain 'stead-fast' and focused, and deliver quality products. At the end of the day, DE will be flooded by consumers.

A lot could be done in terms of creating the ideal towards the attainment of distance education credibility. Distance education institutions need to examine themselves in terms of administrative issues, delivery processes as well as production of quality graduates. 
When setting up distance education institutions, there is need to have this sanctioned by the government as well as the institute of higher learning There is also need to involve governing professional bodies for certain professions such as nursing, medicine or counselling, at the initial stages of program development in order to increase acceptability of the certificate or the degree programs. This ensures that the programs are recognized nationally. There is also need to offer products that are relevant and comparable to the international world. Again, in order to enhance acceptability, efforts should be made to twin up with other renowned DE institutions and share ideas. Students and lecturers could go on an exchange program. Efforts should be made by DE institutions to twin up with some Universities in Europe, where some members of staff could go as visiting lecturers. Staff development programs are encouraged in order to attain cross fertilization of ideas.

In terms of program acceptability, there is need to involve regulatory bodies at the initial planning stages when coming up with training programs. Students should take recognizable examinations. In some instances, there might be need to bench-mark with other institutions in similar business.

The issue of quality is very critical if the ideal is to be created towards the attainment of distance education credibility. This involves a lot of activities which include setting up institutional quality assurance blueprint, which stream-lines all the procedures and processes. Stakeholder involvement is also important as critiques and new ideas can be given to distance education institutions. Setting up of Student bodies will ensure that student interests are addressed.

Staff should also be supported to go on contact leave and sabbatical leave where they will be exposed to other institutions. This will enrich the distance education institutions as these members will come back to their institutions with new ideas and knowledge to improve their own programs. This effort will assist to enhance distance education credibility.

Use of consultants to evaluate programs would also increase distance education credibility. Distance education institutions need to have an effective student support unit that gives guidance and counselling services. Distance education institutions need to increase on their research output. In order to achieve this, there is need for credible libraries and computers with internet connectivity. This would enhance access to current information for research by both students and staff.

Quality learning materials should be developed and these should be reviewed periodically. In terms of assignments and examinations, distance education institutions should have a standardization policy in place. There is need to assist those with knowledge deficit, in distance education in order to enhance appreciation of programs. Systematic standardization in setting and marking of assignments and examinations should be followed. Use of external examiners also enhances distance education credibility. Reward for good student performance is encouraged as this will assist to motivate other students to perform better.

Personnel employed to work at distance education institutions should be qualified in order to create the ideal towards attainment of distance education credibility. Staff development; in-service training as well as carrying out orientation workshops, enhance the institutional knowledge base.

While Distance Education practitioners are struggling to support the learner, there is great need to enhance the issues of quality in order to improve on credibility of Distance Education institutions. It is evident that the need for distance education is inevitable, given the issues of demand and supply. There is need for one to address a variety of issues, which include expertise in administration, quality assurance on processes and program delivery as well as churning out of quality products, the graduates.

It is a fact that distance education institutions deal with larger student numbers as compared to conventional institutions. Staff in distance education are in most cases, overwhelmed with work. As a result, interactivity with students is minimal. This may be a challenge and might call for 'teacher helper,' who would be readily available to students. This type of intervention is appreciable. The Indira Ghandi University of Distance Education, specifically for the Health Sciences Department, utilizes a similar concept, where nurse leaders in various health institutions throughout the country are hired to assist and monitor progress made by students on the Nursing Science Programmes, done by distance education. These are of particular importance as the training is mostly competence based where students need guidance and mentoring in the clinical area. Students need to read the module, at the same time, there is great need for more interactivity, as well as follow-up on practical competencies. One major challenge in DE is the lack of manpower. However noble the idea might be, this needs a considerable financial 'muscle' by the government or institution. From experience, where there are serious financial problems, it has become evident that there is need for donor interventions if success is to be achieved. Issues of quality and learner support dependent on technology, economic status of an institution, high staffing levels who are knowledgeable in DE systems and processes.

The benefits of distance education to individuals, institutions and nations, cannot be over emphasised and examples have been noticed in such developing countries as Botswana, Malawi and Zimbabwe. The intervention and funding by CIDA on the Malawi project of SSTE has significant bearing on the success of project management. An independent consultancy from BOCODOL was hired to evaluate the SSTEP project in Malawi. The consultant gave unbiased recommendations on organisational structure, policies and procedures. This needs to be encouraged if quality assurance is to be achieved. The issues of student support do not only hinge on what the tutor has to the student, but also on the institutional policies, good governance as well as proper utilisation of available technologies. 


\section{REFERENCES}

Modesto, S. T. Tichapondwa and Tau, D. R. (2009): Introducing Distance Education.VUSSC \& BOCODOL. Nachmias, D. Nachmias, C. (1976) Research Methods in the Social Sciences; New York, N.Y. 10010.

Pym F.R (1992) Women and distance education: a nursing perspective Journal of Advanced Nursing 17383 389.

Thorpe, M. (1993) Evaluating Open and Distance Learning.

Longman Group. Redwood Books, Trowbridge, Wiltshire.Willis, B. (1986) Distance Education: A practice guide, New Jersey, Englewood cliffs.

Cite this Article: Chitura M, 2015. Making it happen with distance education: Critical concerns for student support services in Open and Distance Learning. Greener Journal of Educational Research, 5(1):009-016, http://doi.org/10.15580/GJER.2015.1.012315019. 